\title{
Experimental study on flexural behaviour of reinforced concrete beams strengthened with passive and active CFRP strips using a novel anchorage system
}

\author{
Bartosz Piątek $^{1}$ (D) Tomasz Siwowski ${ }^{1}$ D
}

Received: 12 October 2021 / Revised: 17 December 2021 / Accepted: 19 December 2021 / Published online: 14 January 2022

(c) The Author(s) 2022

\begin{abstract}
The paper presents the research on reinforced concrete (RC) beams strengthened with carbon fibre reinforced polymer (CFRP) strips with various configurations in terms of anchoring and tensioning. The five full-scale RC beams with the total length of $6.0 \mathrm{~m}$ were strengthened with passive strips, without and with mechanical anchorages at their ends, as well as with strips tensioned by the novel prestressing system with three various prestressing levels ranging from 30 to $50 \%$ of the CFRP tensile strength. All RC beams were tested under static flexural load up to failure and they were investigated in a full range of flexural behaviour, including the post-debonding phase. The main parameters considered in this study include the use of mechanical anchorages, the effect of tensioning the strips and the influence of the various prestressing levels. Several performance indicators have been established to evaluate the beams' behaviour. The study revealed that the RC beams strengthened using tensioned CFRP strips exhibited a higher cracking, yielding and ultimate moments as compared to the beams with passively bonded CFRP strips. Moreover, increasing the beams' prestressing level has a significant positive influence on the performance of strengthened beams. However, it did not affect the ultimate load-bearing capacity of the beams. The optimal prestressing level for the novel system has been determined as 60\% of CFRP tensile strength.
\end{abstract}

Keywords Anchorage $\cdot$ CFRP strip $\cdot$ Prestressing $\cdot$ RC beams

\section{Introduction}

The flexural strengthening of reinforced concrete (RC) structural elements with externally bonded carbon fibre reinforced polymer (CFRP) strips or sheets has been developing for about 30 years, the first attempts were made by Saadatmanesh and Ehsani [1] and Triantafillou et al. [2]. Currently, it is a widely used and highly effective method for retrofitting RC structures throughout the world and it is a suitable alternative for conventional strengthening methods as steel plate bonding or external prestressing [3]. It is mainly due to the excellent advantages of CFRP material

Bartosz Piątek

piatek@prz.edu.pl

Tomasz Siwowski

siwowski@prz.edu.pl

1 Department of Roads and Bridges, Rzeszow University of Technology, Al. Powstancow Warszawy 12, Rzeszow, Poland in RC strengthening, such as high tensile strength, lightweight, high strength to weight ratio, excellent corrosion and fatigue resistance [4]. The most common way to strengthen the structure with CFRP material is passive bonding to the external concrete surface. However, passively bonded CFRP strips have some limitations. Research proved that only approximately $20-50 \%$ of CFRP tensile strength can be utilised before the failure of strengthening, caused in most cases by the debonding of the strip due to concrete cover failure [5]. Moreover, passive strengthening has hardly any influence on the stiffness of RC elements because of a slight increase in its cross-section and moment of inertia. It can be effectively applied only when the main goal of strengthening is improving an ultimate load-bearing capacity of the structural element, but reducing the deflection or cracks width in concrete is not required [6].

To utilise the great potential of the CFRP strips and to obtain the best strengthening effects, the strips can be tensioned before bonding and fixing them to the structure to be strengthened [7]. CFRP tensioning allows for increasing the ultimate load-bearing capacity and stiffness of strengthened 
structural elements and thus enhances the CFRP material utilisation in comparison with a passive external bonding technique [8]. Currently, all over the world, intensive research is being undertaken for better understanding static [9], fatigue [10] and long-term behaviour [11] of RC elements strengthened with this technology as well as to develop a prestressing system that can be applied on-site and used in practical applications [12]. The most important part of the prestressing system is anchorage of the CFRP strip [13]. Wide reviews of anchoring techniques were published, among others, by Mohee et al. [14] and Kalfat et al. [15]. During the last 20 years, wide research in this field has been conducted as a result of which several CFRP post-tensioning systems were developed. Some of these systems have already been implemented on-site and now they are used in practical applications, like the first system which uses anchoring steel plates and small tensioning device developed in Germany [16], the system with composite anchoring head [17] or the first Swiss system [18]. There are also novel systems without typical anchorages, which uses thermal [19] or mechanical [20] gradual reduction of the prestressing force. Lots of other solutions are still in the development phase like systems tested by Woo et al. [21] or Yang et al. [22].

The effectiveness of strengthening RC structures using CFRP strips can be measured with some indicators (ratios) which compare parameters of strengthened and unstrengthened elements in ultimate and serviceability limit states. The often-used indicators let to evaluate the effect of strips anchoring (or not) [23], the effect of strengthening method (passive or active) [24] as well as the effect of applying various prestressing levels on the structural performance of the strengthened beams [25]. To obtain these indicators, the typical parameters characterising the behaviour of the RC beams under static loads, such as cracking patterns, deflection, strains or failure modes should be recorded during testing. Furthermore, because of the scale effect, the valuable quantitative results can be obtained only in research on fullscale (or close to actual) elements [26].

In this paper, the results of the experimental study on five full-scale RC beams strengthened with CFRP strips and tested under four-point bending load up to failure are presented. Two beams were strengthened with passively bonded CFRP strips, while three remaining beams were prestressed by the newly developed CFRP strengthening system [27]. To evaluate the results of these two methods of strengthening a couple of performance indicators describing the beams' behaviour under static load were determined. The typical parameters characterising the behaviour of the RC beams under static loads, such as cracking patterns, deflection, strains or failure modes were recorded and the strengthening efficiency in three phases of beams' behaviour (uncracked, post-cracked and post-yielded), the level of a CFRP strip utilisation, the ratio of ultimate load-bearing capacity to debonding moment as well as the ratio of plastic displacement after strip debonding were taken into account in the discussion of tests results. Finally, three main aspects of strengthening were evaluated using these parameters: the effect of strips anchoring, the effect of strips tensioning as well as the effect of applying various prestressing levels (30\%, $40 \%$ and $50 \%$ of CFRP tensile strength) on the structural performance of the strengthened beams.

\section{Research significance}

The current research includes the static tests on the fullscale RC beams strengthened with passive and active (tensioned) CFRP strips. This issue has been extensively studied and lots of research papers can be found in the literature [28]. However, the behaviour of the prestressed RC beam under static load, especially in the post-debonding phase closed to failure, is highly dependent on the particular prestressing system applied for strengthening [29]. The current research, which results are presented in this paper, had two main objectives. The first objective was the evaluation of the $\mathrm{RC}$ beams strengthened with the novel CFRP prestressing system in a full range of their behaviour under static load, including post-debonding phase and failure modes. The second objective was associated with the novel prestressing system itself. The implementation of the novel system on the full-scale RC beams and its extensive tests up to failure allowed for experimental verification of the efficiency and feasibility of the system in laboratory conditions. The results of the achievement of both objectives, and the results of previous authors' research works [30] enabled implementation of the system on-site [31].

Based on the literature review on the factors which influence the behaviour of the RC beams strengthened with CFRP strips three main aspects have been selected to investigate: the effect of the strips anchoring (or not)based on the comparison between B0 and B0A beams, the effect of strengthening method (passive or active) - differences between passively strengthened beams (B0, B0A) and prestressed (B30, B40, B50) and the effect of prestressing level-based on the comparison of the behaviour of B30, B40 and B50 beam prestressed with 30\%, $40 \%$ and $50 \%$ of CFRP tensile strength, respectively. The last aspect seems to be the most important from the point of view of the newly developed prestressing system. The optimal prestressing level has already been determined and corresponds to about $60 \%$ of the tensile strength of the strip [5]. Nevertheless, the optimal level of CFRP strip tensioning depends on the individual characteristics of the applied strengthening system and the capabilities of its components, in particular strip anchors and tensioning device. That is why this issue has been particularly considered in the current study. 


\section{Materials and methods}

\subsection{Material properties}

All materials used to manufacture and strengthen the RC beams were tested to obtain their mechanical parameters before the beams' investigation. RC full-scale beams were designed to be made of concrete $\mathrm{C} 45 / 55$ class (according to European standards $[32,33]$ ) with a maximum aggregate size of $16 \mathrm{~mm}$, whereas the reinforcing steel of B500SP grade was used for reinforcement. The mean compression concrete strength $\left(f_{\mathrm{cm}}\right)$ was equal to $62.2 \mathrm{MPa}$, while minimum compression strength $\left(f_{\text {ci,min }}\right)$ was $61.3 \mathrm{MPa}$, according to the material tests carried out in this study. The remaining concrete strength parameters (i.e. modulus of elasticity, tensile strength, ultimate strain) were adopted following the standard EN 1992-1-1 [33] and used in calculations. To determine the yield strength, tensile strength and modulus of elasticity, five specimens of reinforcing bars with a diameter of $25 \mathrm{~mm}$ were subjected to axial tensile tests according to the standard EN 10,002-1 [34]. The mean yield strength of reinforcing steel $\left(f_{\mathrm{yk}}\right)$ was $522 \mathrm{MPa}$, the mean tensile strength $\left(f_{\mathrm{tk}}\right)$ was $628 \mathrm{MPa}$, the characteristic strain under maximum load was $10.9 \%$ and the mean value of Young modulus was $192 \mathrm{GPa}$.

The novel CFRP strengthening system typically uses high-strength UHS 614 strips with a cross-section of $1.4 \mathrm{~mm} \times 60 \mathrm{~mm}$ and the ultimate tensile strength $\left(f_{\mathrm{fu}}\right)$ of $3200 \mathrm{MPa}$, modulus of elasticity of $160 \mathrm{GPa}$ and the strain at failure of about $2 \%$, as declared by the strips' manufacturer. These parameters have been confirmed by the tests according to standard ISO 527 [35], on 9 specimens with a length of $600 \mathrm{~mm}$ and full cross-section: the difference between the declared material parameters and those obtained by the tests was less than $4 \%$. Finally, the system adhesive to be used for strip bonding was checked in the appropriate material tests according to standard EN 1465 [36]. The epoxy-based adhesive is characterised by flexural strength of $53.3 \mathrm{MPa}$, compressive strength of $107 \mathrm{MPa}$, flexural modulus of elasticity of $10.3 \mathrm{GPa}$, adhesion to dry concrete of $4.6 \mathrm{MPa}$ and glass transition temperature of $120^{\circ} \mathrm{C}$.

\subsection{Test beams}

The flexural tests were carried out on six full-scale RC beams marked as shown in Table 1 . The beams had a rectangular cross-section of $0.50 \mathrm{~m} \times 0.42 \mathrm{~m}$ and a total length of approximately $6.0 \mathrm{~m}$. The top and bottom longitudinal reinforcement comprised three bars with a diameter of $25 \mathrm{~mm}$ with a spacing of $185 \mathrm{~mm}$ (the steel reinforcement ratio $\rho_{\mathrm{s}}=0.79 \%$ ), whereas the stirrups with a spacing of $80-120 \mathrm{~mm}$ and a diameter of $12 \mathrm{~mm}$ were applied as a shear reinforcement (Fig. 1). The concrete cover was $25 \mathrm{~mm}$. At the ends of the beams, a middle bar of lower reinforcement was bent up to make a place for anchorage installation as well as to enhance the shear capacity of the beams. The $\mathrm{RC}$ beams were over-reinforced against shear and designed to obtain flexural failure. All beams were cast in the form of a common precast beam used in Poland. After 28 days
Table 1 Parameters of beams strengthening

\begin{tabular}{|c|c|c|c|c|c|}
\hline Beam (method) & $\begin{array}{l}\text { Prestressing level } \\
{[-]}\end{array}$ & $\begin{array}{l}\text { Prestressing force } \\
{[\mathrm{kN}]}\end{array}$ & $\begin{array}{l}\text { Initial CFRP } \\
\text { strain } \\
{[\% \circ]}\end{array}$ & $\begin{array}{l}\text { Initial CFRP } \\
\text { stress } \\
{[\mathrm{MPa}]}\end{array}$ & Anchorages \\
\hline $\mathrm{BC}$ (control) & \multicolumn{5}{|c|}{ Control beam (unstrengthened) } \\
\hline B0 (passive) & $0 \% f_{\text {fu }}$ & - & - & - & no \\
\hline B0A (passive) & $0 \% f_{\text {fu }}$ & - & - & - & yes \\
\hline B30 (active) & $30 \% f_{\text {fu }}$ & $2 \times 81$ & 6.0 & 960 & yes \\
\hline B40 (active) & $40 \% f_{\text {fu }}$ & $2 \times 108$ & 8.0 & 1280 & yes \\
\hline B50 (active) & $50 \% f_{\text {fu }}$ & $2 \times 134$ & 10.0 & 1600 & yes \\
\hline
\end{tabular}

Longitudinal section

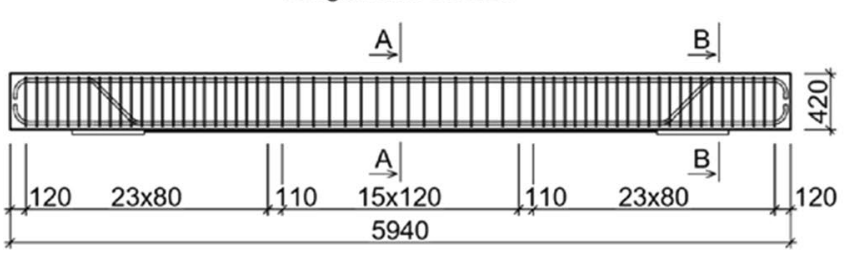

Cross-section A-A

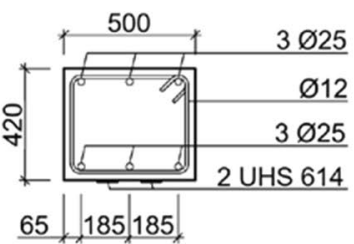

Cross-section B-B

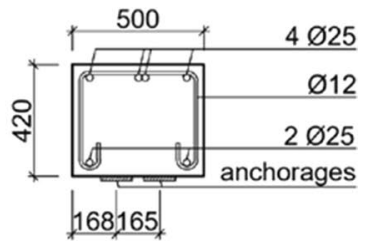

Fig. 1 Beams' reinforcement (dimensions in [mm]) 
the concrete was set and the beams were strengthened with CFRP strips.

The first beam (marked BC) was not strengthened and served as a control (reference) beam. Each of the other beams was strengthened by two CFRP strips with a length of $5.0 \mathrm{~m}$ (including anchorages, if used) placed symmetrically on the beam' bottom surface with $165 \mathrm{~mm}$ spacing. The CFRP reinforcement ratio $\left(\rho_{\mathrm{f}}\right)$ was equal to $0.08 \%$ and the equivalent reinforcement ratio including steel rebars $\left[\rho_{\mathrm{f}, \mathrm{eq}}=\rho_{\mathrm{s}}+\rho_{\mathrm{f}}\left(E_{\mathrm{f}} / E_{\mathrm{s}}\right)\right]$ was equal to $0.86 \%$. The beams B0 and BOA were strengthened with passively bonded strips (not tensioned). The ends of strips bonded to the B0A beam were anchored with the double-sided system steel anchorages. The remaining three beams (B30-B50) were strengthened with the novel system and prestressed with various prestressing levels: $30 \%, 40 \%$ and $50 \%$ of the CFRP tensile strength $\left(f_{\mathrm{fu}}\right)$ subsequently. The corresponding prestressing force of the subsequent beams amounted to 162, 216 and 268 $\mathrm{kN}$, respectively. The detailed strengthening parameters of all tested beams are listed in Table 1 .

\subsection{Beams strengthening}

The beams B30-B50 were strengthened with the new Polish CFRP prestressing system developed by the authors in the frame of this research project [27]. The system consists of a CFRP strip with a cross-section of $1.4 \mathrm{~mm} \times 60 \mathrm{~mm}$ with special steel anchorages mounted on both ends of the strip and a relevant tensioning device driven by a manual pump (Fig. 2). The system uses two kinds of anchorages: an active anchorage combined with the tensioning device and a passive one at the second end of the CFRP strip. The single anchorage is made of three thin steel sheets (two external and one internal) connected along their edges by welding to create a pocket, in which the end of CFRP strip (approximately $300 \mathrm{~mm}$ length) is fixed and bonded to the external sheets with a special epoxy-based adhesive. Before welding, the inner surfaces of the sheets are sandblasted and cleaned with a substance based on acetone. It is followed by gripping both materials (steel plates and CFRP strip in-between) with mechanical fasteners with small diameter: $4 \mathrm{~mm}$ rivets (N-type) or $6 \mathrm{~mm}$ high-strength bolts (S-type). The anchorages transfer the tension load from the tensioning device to the strip in three ways: internal bonding, friction and gripping, simultaneously. The anchorages have two functional areas: external and internal. The strip is clamped, bonded and gripped within the internal area. The external area comprises holes for anchors, attaching the anchorage to the concrete surface, and threaded holes for mounting the tensioning device (in active anchorage only).

In the current study, both anchorage types were used: for anchoring the passive strips to the B0A beam, anchorages with bonded/riveted joints (N-type) with 34 rivets with $4 \mathrm{~mm}$ diameter were used. The tensioned strips in the B30-B50 beams were installed using bonded/bolted (S-type) anchorages with 36 high-strength friction grip bolts with $6 \mathrm{~mm}$ diameter. The development of both anchorages used in the strengthening system is described in details elsewhere (N-type [37], S-type [38]).

The second key element of the strengthening system is a tensioning device. It consists of three separately installed elements: guide rails, movable carriage (which is bolted to the active anchorage during strip tensioning) and hydraulic jack with resisting block. The tensioning device is compatible with the active anchorage of the CFRP strip. It is equipped with a hydraulic jack that can generate a force for tensioning the CFRP strips up to the required level.

Before the installation of the strip, RC beams were set on the assembly station in the same scheme as during the tests (Fig. 3a). Strengthening was carried out on the bottom surfaces of the beams to take into account a dead load of the beams. The concrete surfaces were grinded, dedusted and degreased. In the case of B0 beam-strengthened passively without anchorages, an adhesive layer was applied to previously cleaned CFRP strips, which were then bonded to the surface of the beams. The CFRP strips equipped with anchorages (for B0A-B50 beams) were fabricated in a precast workshop as "tailor-made". In the case of the B0A beam, at first holes for the anchors were drilled, then the strips were adhesively bonded to the concrete surface and

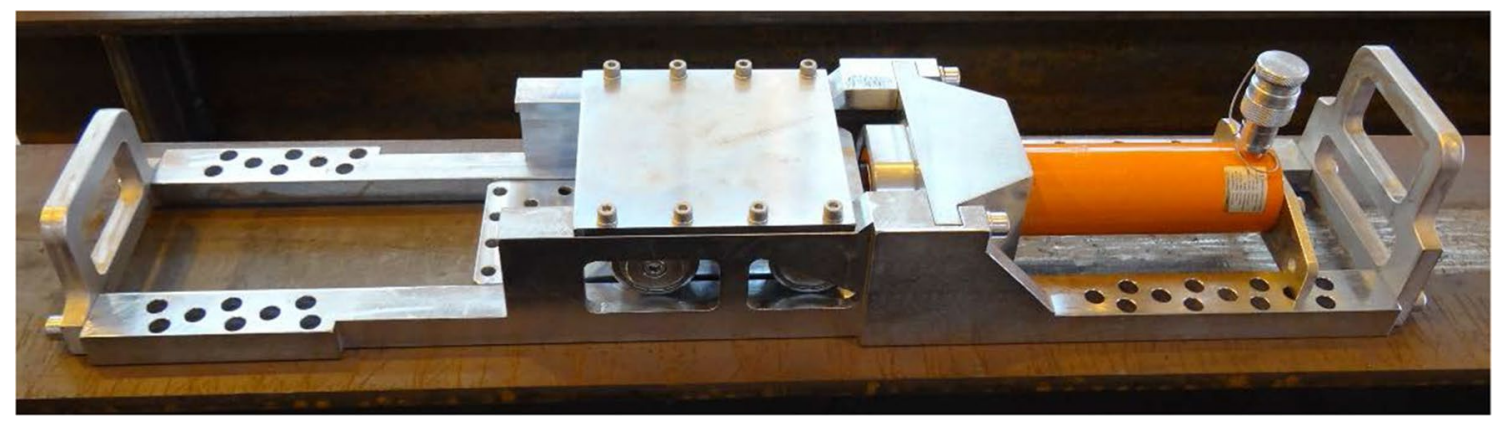

Fig. 2 Novel CFRP prestressing system 


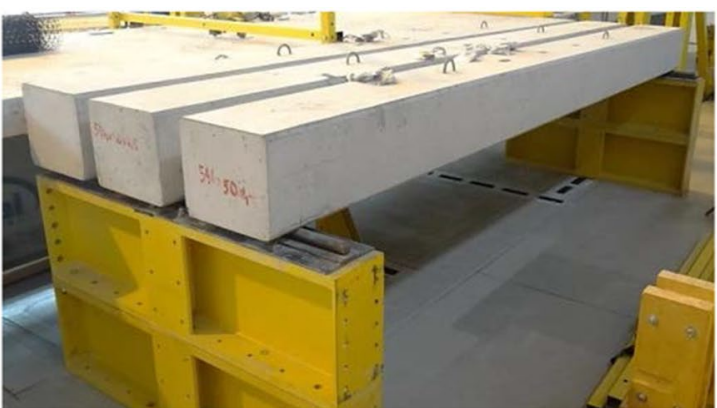

(a)

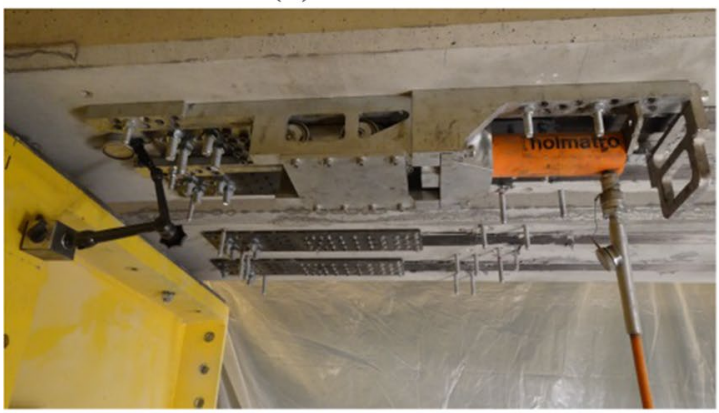

(c)

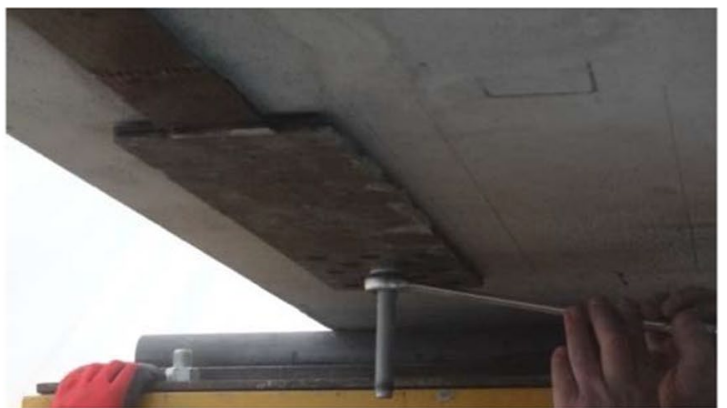

(b)

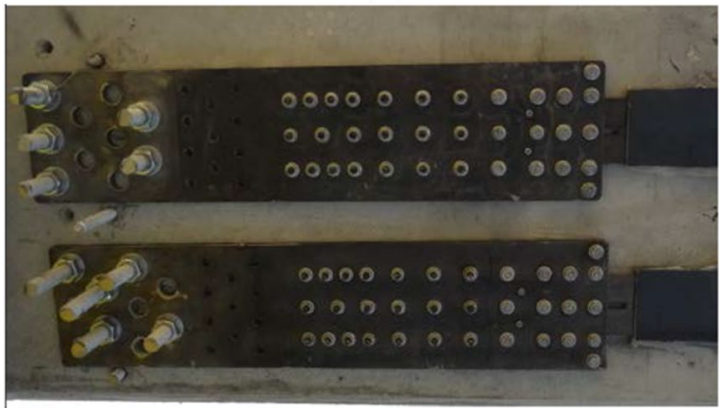

(d)

Fig. 3 Strengthening of the beams: a the beams set on the assembly station, $\mathbf{b}$ installation of passive anchorage on the B0A beam (N-type), $\mathbf{c}$ strip tensioning, $\mathbf{d}$ active anchorages (S-type) installed on the B30 beam

anchored at their ends using N-type anchorages by mechanical anchors (Fig. 3b). The beams B30-B50 were strengthened using a novel prestressing system. At first, the passive anchorage was mounted to the concrete surface, then the tensioning device was installed at the active side (Fig. 3c). The installation of the tensioning device consists of mounting the guide rails to the concrete surface, inserting the active anchorage between the two rails, bolting the movable carriage to the active anchorage and installing the hydraulic jack with the resisting block. When the tensioning device was ready the strip was tensioned up to the required level of prestressing force (trial tensioning), the holes for mounting the active anchorage were drilled and the tensioning was released. Then the adhesive was applied to the CFRP strip and the concrete surface. After application of the adhesive, the CFRP strip was tensioned again in the same manner (Fig. 3c), the active anchorage was fixed to the beam with mechanical anchors bolted in pre-drilled holes and the tensioning device was removed (Fig. 3d). In the last installation step, the CFRP strip was pressed to the concrete surface along the whole length of the strip and the adhesive excess was removed. After setting the adhesive, the beam was ready to be loaded.

\subsection{Test method and instrumentation}

The flexural tests were carried out at a special adjustable lab stand. Loading was applied by an Instron Schenck PL630

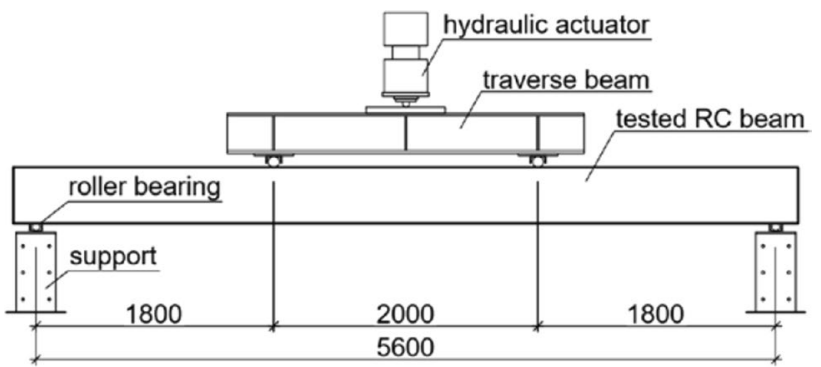

Fig. 4 Test setup of the beams (dimensions in [mm])

hydraulic actuator with a maximum load force of $630 \mathrm{kN}$. A four-point bending scheme was applied using a steel traverse beam, spreading the load from the one actuator into two loading points (Fig. 4). The beams were set as simply supported with a span length of $5.6 \mathrm{~m}$. They were supported point-wise on roller bearings. The view of the beam on the lab stand is presented in Fig. 5.

The beams were loaded in a range of $100-450 \mathrm{kNm}$ at several stages up to failure. The load at every stage was defined as the bending moment induced by the hydraulic actuator. The maximum load at the subsequent stages was increased in steps of $50 \mathrm{kNm}$. At the final load stage, the beams were loaded until failure. The tests were conducted with a force-controlled rate of $1 \mathrm{kN} / \mathrm{s}$ up to steel yielding and then manually with displacement control. During the tests, the load, the displacements of the beams, the strains 


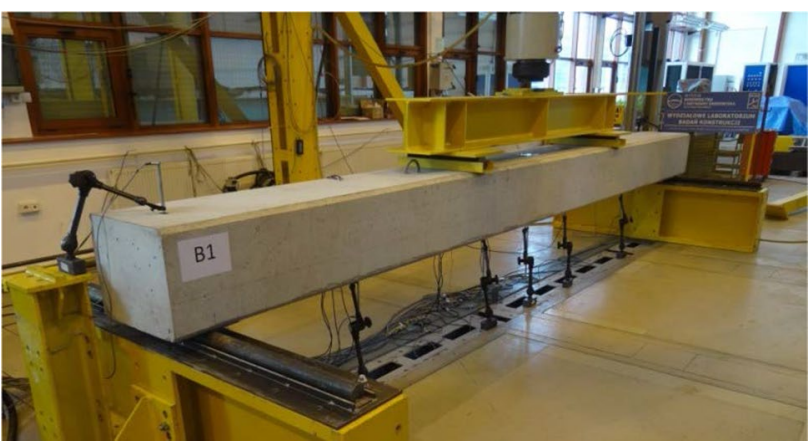

Fig. 5 RC beam on the lab stand

of concrete and steel bars as well as the strains of the CFRP strips were measured continuously. For each beam, concrete strains were measured in six points in the zone of the constant bending moment: three points on top $(\mathrm{BG} / 3-\mathrm{BG} / 5)$ and bottom (BD/3-BD/5) beams' surfaces. Steel strains were measured in 12 points (four points on the reinforcing bars in the top (SGL, SGP) and bottom (SDL, SDP) corners in three beam's cross-sections: S1, S3 and S4). CFRP strains were measured along the entire strip in the points spaced every $600 \mathrm{~mm}$, which constituted a total of 18 measurement points (TL/0-TL/8, TP/0-TP/8) in the case of the B0 beam and 14 points (TL/1-TL/7, TP/1-TP/7) in the case of other strengthened beams. The displacements were measured at 7 points (P1-P7) along the entire beam. The location of strains and displacements measuring points is presented in Fig. 6. The linear variable displacement transducers (LVDT) with a $100 \mathrm{~mm}$ range and an accuracy of $0.01 \mathrm{~mm}$ were used for deflection measurement, while all strains were measured using $10 \mathrm{~mm}$ electric strain gauges with an accuracy of $0.001 \%$. All LVDTs and strain gauges were connected via a set of QuantumX MX840A amplifier modules to a computer with Catman Easy data acquisition software. The measurements were recorded at a frequency of $1 \mathrm{~Hz}$. For each loading stage, a detailed morphology of concrete cracking (on side beam's surfaces) was assessed and recorded. The concrete cracking was controlled visually and supported with a crack width measurement. Finally, the failure modes were identified in detail and recorded using a video camera.

\section{Experimental results}

\subsection{Crack patterns}

Figure 7 shows a comparison of the cracks patterns on the side surface of all tested beams under the load of $250 \mathrm{kNm}$, approximately corresponding to the characteristic load of B40 beam calculated according to Eurocodes [39, 40]. The
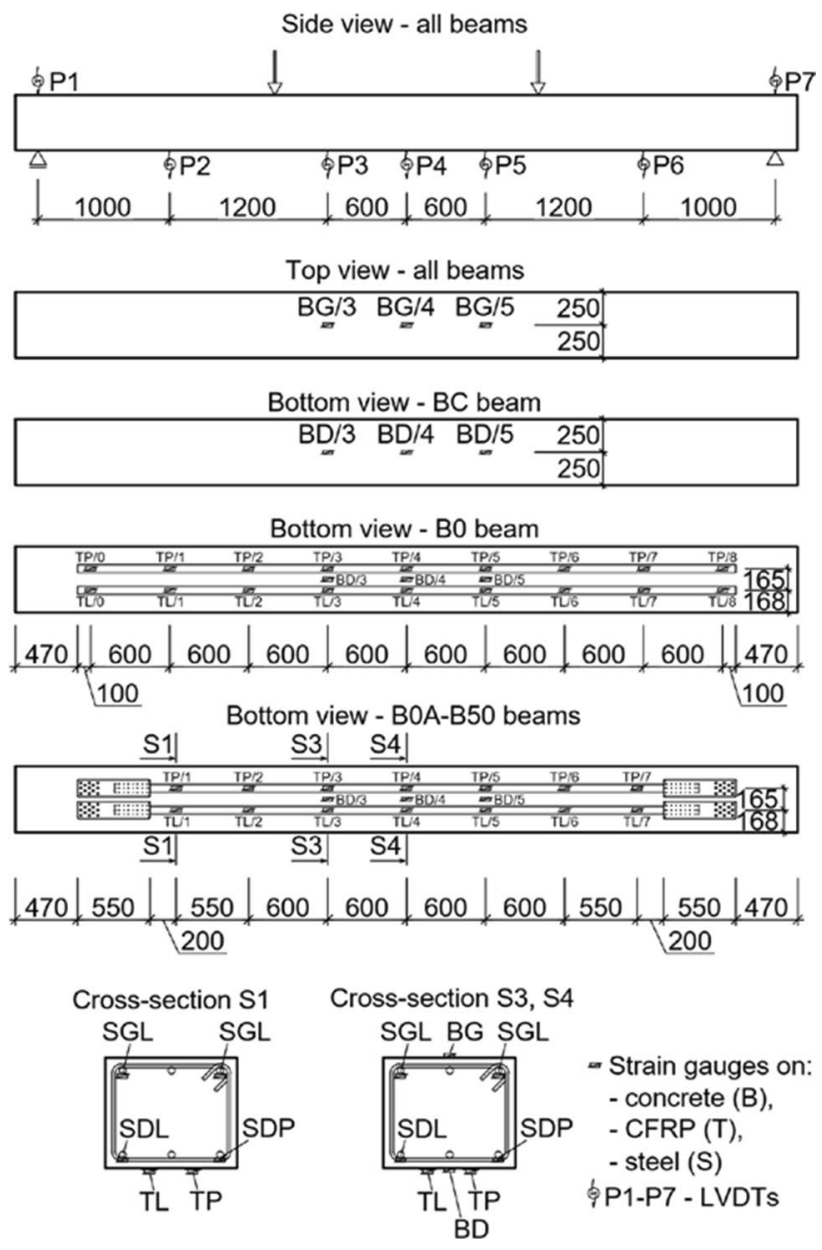

Fig. 6 Locations of measuring points (dimensions in [mm])

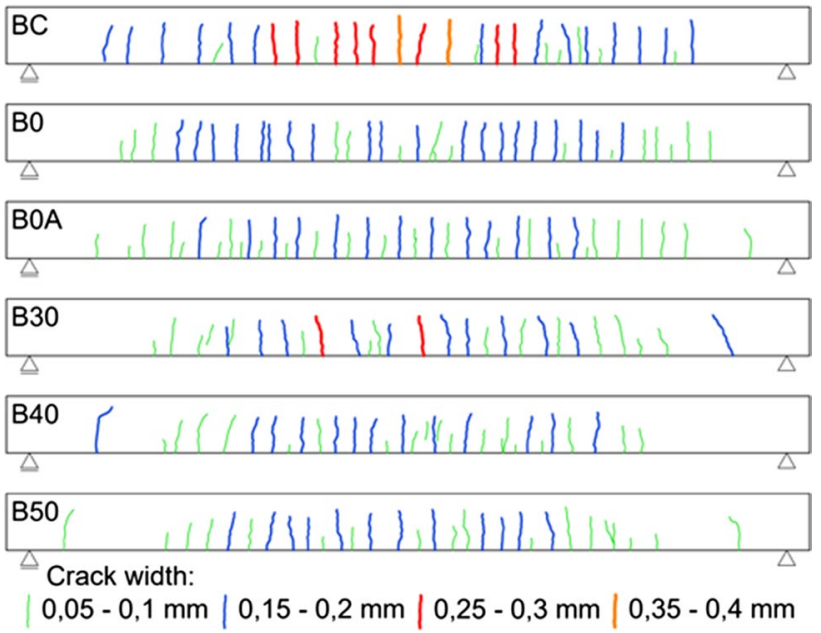

Fig. 7 Beam cracking under the load of $250 \mathrm{kNm}$ 
Table 2 Crack characteristics in tested beams under the load of 250 $\mathrm{kNm}$

\begin{tabular}{llll}
\hline Beam & $\begin{array}{l}\text { Maximum crack } \\
\text { width } \\
{[\mathrm{mm}]}\end{array}$ & $\begin{array}{l}\text { Number of } \\
\text { cracks } \\
{[-]}\end{array}$ & $\begin{array}{l}\text { Total crack width } \\
{[\mathrm{mm}]}\end{array}$ \\
\hline BC & 0.40 & 32 & 6.00 \\
B0 & 0.20 & 36 & 4.45 \\
B0A & 0.20 & 38 & 3.95 \\
B30 & 0.25 & 28 & 3.50 \\
B40 & 0.20 & 32 & 3.45 \\
B50 & 0.20 & 29 & 3.40 \\
\hline
\end{tabular}

number of cracks and the total crack width occurring under this load are listed in Table 2.

\subsection{Strain distribution}

\subsubsection{Concrete}

The concrete strains $\left(\varepsilon_{\mathrm{c}}\right)$ measured at the top and bottom surface of all tested beams under the load of $250 \mathrm{kNm}$ as well as under the failure load are presented in Tables 3 and 4 , respectively. Due to subsequent cracks occurring in the tension zones of the beams, the strains measured in the tension zone are relevant only in the uncracked behaviour of the

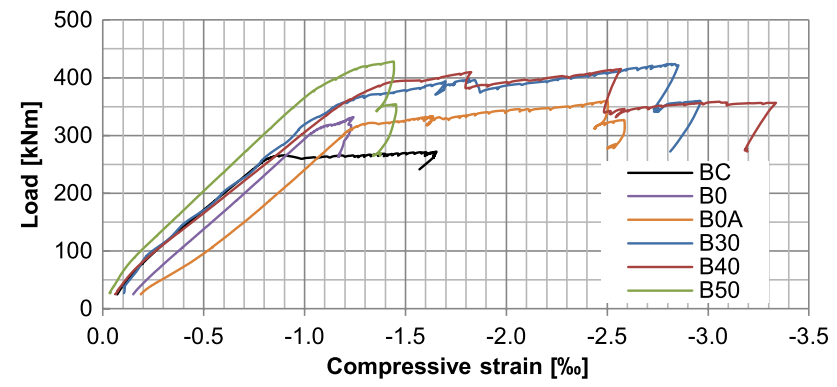

Fig. 8 Comparison of load-concrete compressive strain $\left(\mathrm{M}-\varepsilon_{\mathrm{c}}\right)$ plots for all tested beams (measurement point BG4)

beams. Figure 8 shows exemplary load-compressive strain plots $\left(\mathrm{M}-\varepsilon_{\mathrm{c}}\right)$ for subsequent beams at the final failure loading stage recorded in the measurement point BG4. The concrete strains curves in the plots do not start from the zero points because of the residual (permanent) strains remaining after the previous load steps.

\subsubsection{Steel reinforcement}

The steel strains $\left(\varepsilon_{\mathrm{s}}\right)$ measured in upper and lower longitudinal reinforcing bars of all tested beams under the exemplary load of $250 \mathrm{kNm}$ as well as under failure load in the area of constant bending moment (section S2 and
Table 3 Concrete strains $\left(\varepsilon_{\mathrm{c}}\right)$ in tested beams under the load of $250 \mathrm{kNm}[\%$ o]

\begin{tabular}{lllllll}
\hline Measuring point & \multicolumn{7}{l}{ Beam } & \multicolumn{1}{l}{} \\
\cline { 2 - 6 } & BC & B0 & B0A & B30 & B40 & B50 \\
\hline BG3 & -1.13 & -0.77 & -0.80 & -0.75 & -0.62 & -0.68 \\
BG4 & -0.75 & -0.76 & -0.95 & -0.72 & -0.77 & -0.61 \\
BG5 & -1.16 & -0.86 & -1.02 & -0.85 & -0.78 & -0.67 \\
BD3 & 1.23 & 1.02 & $*$ & -0.04 & 0.06 & 0.70 \\
BD4 & 0.15 & 0.39 & $*$ & 0.78 & $*$ & 0.16 \\
BD5 & -0.11 & 2.43 & -0.07 & 0.14 & 0.08 & $*$ \\
\hline
\end{tabular}

*Damaged strain gauge

\begin{tabular}{lllllll}
\hline Measuring point & \multicolumn{6}{l}{ Beam (failure load $[\mathrm{kNm}])$} \\
\cline { 2 - 7 } & BC & B0 & B0A & B30 & B40 & B50 \\
& 272 & 332 & 361 & 424 & 415 & 428 \\
\hline BG3 & -2.15 & -1.18 & -2.27 & -3.43 & -1.64 & -1.64 \\
BG4 & -1.65 & -1.24 & -2.50 & -2.82 & -2.56 & -1.44 \\
BG5 & -1.64 & -1.51 & -2.44 & -2.98 & -3.20 & -1.49 \\
BD3 & 1.54 & 2.19 & $*$ & 0.30 & 0.34 & $*$ \\
BD4 & 0.25 & 0.71 & $*$ & $*$ & $*$ & 1.22 \\
BD5 & -0.13 & $*$ & -0.14 & 0.12 & 0.06 & $*$ \\
\hline
\end{tabular}

*Damaged strain gauge
Table 4 Concrete strains $\left(\varepsilon_{\mathrm{c}}\right)$ in tested beams under failure loads [\%o] 
Table 5 Steel strains $\left(\varepsilon_{\mathrm{s}}\right)$ in tested beams under the load of $250 \mathrm{kNm}[\%$ o
Table 6 Steel strains $\left(\varepsilon_{\mathrm{s}}\right)$ in tested beams under the failure loads $[\%$ o]

\begin{tabular}{|c|c|c|c|c|c|c|}
\hline \multirow[t]{2}{*}{ Measuring point } & \multicolumn{6}{|l|}{ Beam } \\
\hline & $\mathrm{BC}$ & B0 & $\mathrm{B} 0 \mathrm{~A}$ & B30 & B40 & B50 \\
\hline SGP3 & -0.58 & -0.54 & -0.71 & -0.55 & -0.62 & -0.71 \\
\hline SGL3 & -0.68 & -0.60 & -0.64 & -0.46 & -0.68 & -0.70 \\
\hline SGP4 & -0.73 & -0.74 & -0.76 & -0.65 & -0.64 & -0.57 \\
\hline SGL4 & -0.61 & -0.65 & -0.63 & -0.47 & -0.74 & -0.79 \\
\hline SDP3 & 2.95 & 2.10 & 2.35 & 1.76 & 1.78 & 1.61 \\
\hline SDL3 & 2.48 & 2.34 & 2.06 & 2.01 & 1.68 & 1.72 \\
\hline SDP4 & 3.48 & 2.33 & 2.54 & 1.15 & 1.79 & 1.75 \\
\hline SDL4 & 3.22 & 2.47 & 2.30 & 1.84 & 1.87 & 1.54 \\
\hline
\end{tabular}

\begin{tabular}{lllllll}
\hline Measuring point & \multicolumn{6}{l}{ Beam (failure load $[\mathrm{kNm}])$} \\
\cline { 2 - 7 } & BC & B0 & B0A & B30 & B40 & B50 \\
& 272 & 332 & 361 & 424 & 415 & 428 \\
\hline SGP3 & -0.85 & -0.79 & -1.20 & -1.02 & -1.20 & -1.28 \\
SGL3 & -0.89 & -0.87 & -1.10 & -0.61 & -1.39 & -1.32 \\
SGP4 & -1.08 & -1.14 & -1.29 & -1.26 & -1.38 & -1.08 \\
SGL4 & -0.80 & -0.96 & -1.18 & -0.72 & -1.60 & -1.37 \\
SDP3 & $*$ & 3.44 & $*$ & $*$ & $*$ & $*$ \\
SDL3 & $*$ & 4.25 & 1.96 & $*$ & $*$ & $*$ \\
SDP4 & $*$ & 4.77 & $*$ & $*$ & 7.44 & $*$ \\
SDL4 & $*$ & 2.92 & $*$ & 1.95 & $*$ & $*$
\end{tabular}

*Damaged strain gauge

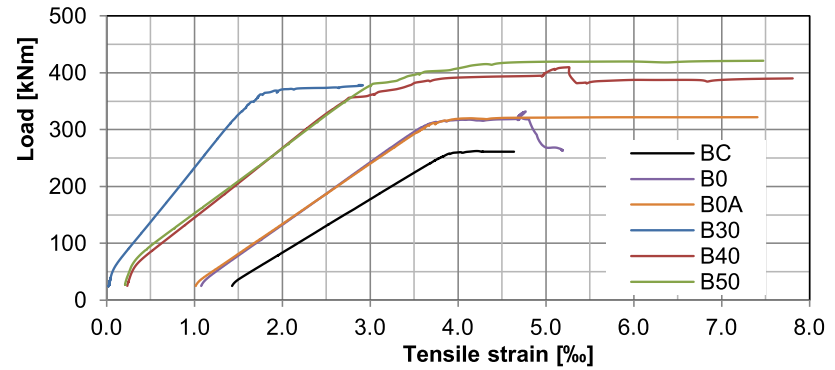

Fig. 9 Comparison of load-steel tensile strain $\left(\mathrm{M}-\varepsilon_{\mathrm{s}}\right)$ plots for all tested beams (measurement point SDP4)

S4) are presented in Tables 5 and 6, respectively. Figure 9 shows exemplary load-steel strains plots in the tension zone resulting from loading $\left(\mathrm{M}-\varepsilon_{\mathrm{s}}\right)$ for subsequent beams at the last loading stage recorded in the measurement point SDP4. The steel strains curves in the plots do not start from the 0,0 point because of the residual (permanent) strains remaining after the previous load steps.

\subsection{CFRP strips}

The plots of CFRP strains $\left(\varepsilon_{\mathrm{f}}\right)$ distributions (excluding initial strains caused by tensioning) along the strips for all strengthened beams under selected load levels, including failure load, are presented in Fig. 10. Figure 11 shows an exemplary load-CFRP strain plot $\left(\mathrm{M}-\varepsilon_{\mathrm{f}}\right)$ for subsequent beams at the final loading stage recorded in the measurement point TL4.

\subsection{Displacements}

The comparison of displacements along the beams' length (P1-P7) for all tested beams under the load of $250 \mathrm{kNm}$ is presented in Fig. 12. Figure 13 shows a comparison of load-displacement (M- $\Delta)$ plots for all tested beams in the full load range until failure measured in the middle of the beam span ( $\mathrm{P} 4$ measuring point).

\subsection{Ultimate load and failure modes}

The main experimental output in the form of ultimate loads (bending moments) or deformations for all beams 


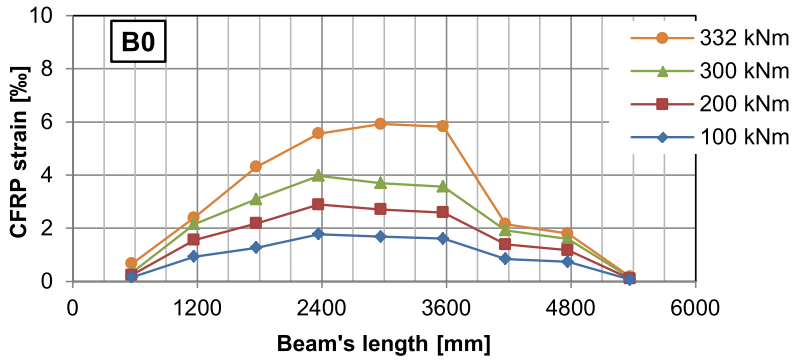

(a)

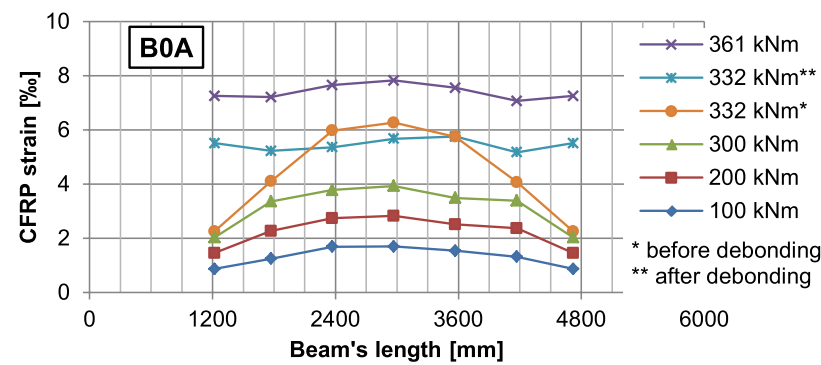

(b)

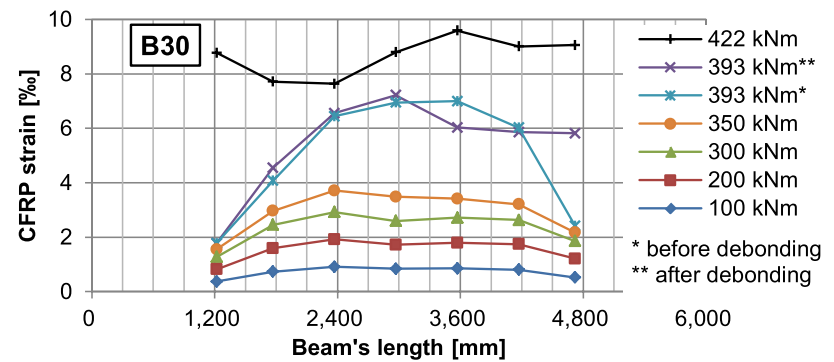

(c)

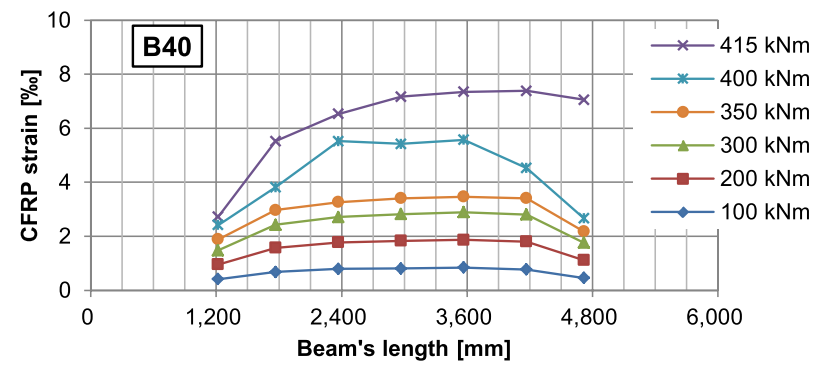

(d)

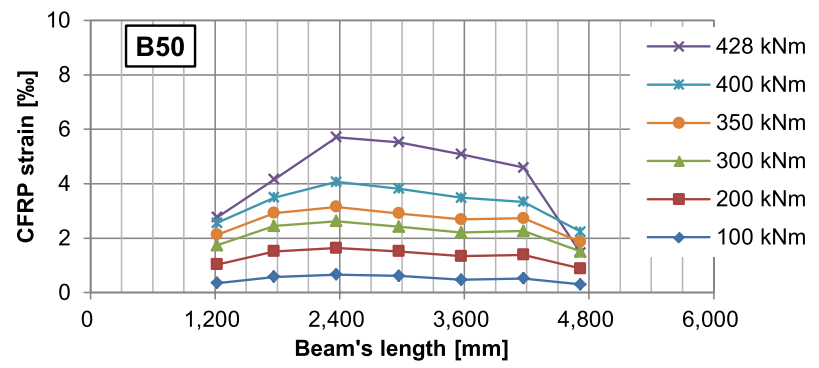

(e)

Fig. 10 CFRP strain distribution along the strip in all strengthened beams: a B0, b B0A, c B30, d B40, e B50

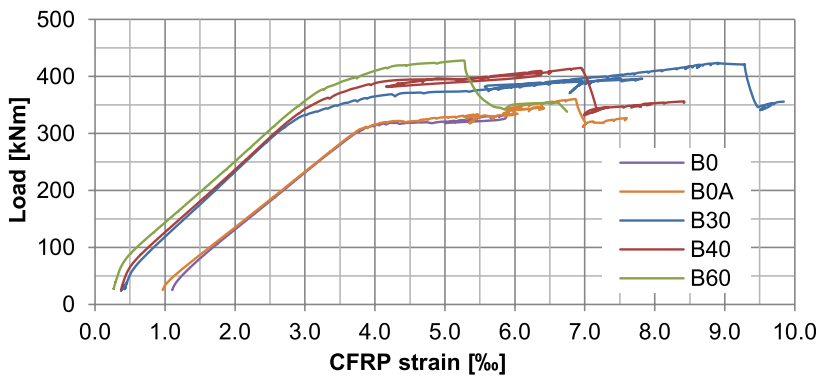

Fig. 11 Comparison of the load-CFRP strain $\left(\mathrm{M}-\varepsilon_{\mathrm{f}}\right)$ plots for all strengthened beams (measuring point TL4)

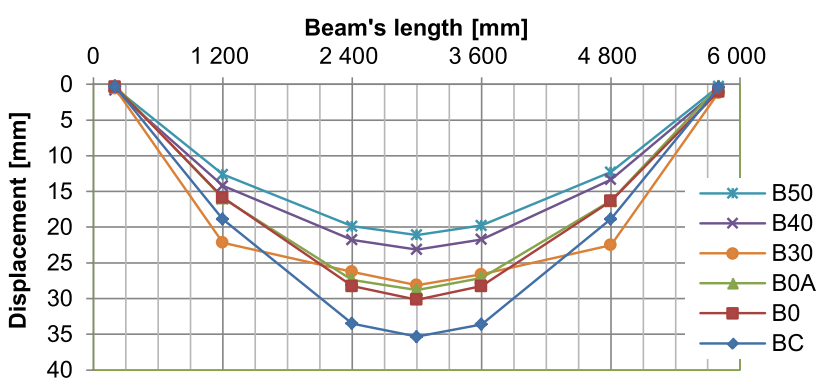

Fig. 12 Comparison of displacements for all beams under the load of $250 \mathrm{kNm}$

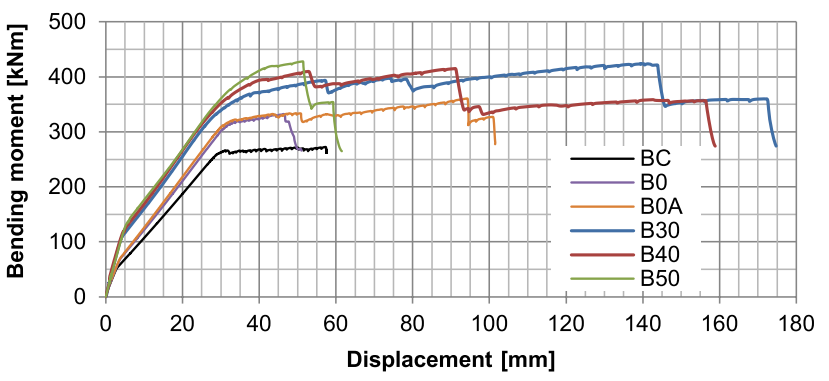

Fig. 13 Comparison of the load-displacement (M- $\Delta$ ) plots in the middle of the span for all tested beams (measuring point $\mathrm{P} 4$ )

is summarised in Table 7. The maximum CFRP strains at failure (including the initial strains induced by tensioning and equalled $6 \%$, $8 \%$ and $10 \%$ o for beams B30, B40 and B50, respectively) and the failure mode descriptions were presented in the table as well. For each tested beam, the values of cracking, yielding, strip debonding and failure moment were determined based on experimental records. The ultimate load-bearing capacity (ultimate moment) is defined as the maximum value of bending moment that was applied during the test until the beam failed. In the case of the control beam (BC), the ultimate moment was assumed when the testing load could not be increased (after steel yielding). In the case of the CFRP strengthened 
Table 7 The main output of the beams' tests

\begin{tabular}{|c|c|c|c|c|c|c|c|}
\hline \multirow[t]{3}{*}{ Beam } & Cracking moment & Yielding moment & $\begin{array}{l}\text { Debond- } \\
\text { ing } \\
\text { moment }\end{array}$ & Ultimate moment & $\begin{array}{l}\text { Ultimate } \\
\text { deflec- } \\
\text { tion }\end{array}$ & $\begin{array}{l}\text { CFRP } \\
\text { strain at } \\
\text { failure }\end{array}$ & Failure mode \\
\hline & $\mathrm{M}_{\mathrm{cr}}$ & $\mathrm{M}_{\mathrm{y}}$ & $\mathrm{M}_{\mathrm{d}}$ & $\mathrm{M}_{\mathrm{u}}$ & $\Delta_{\mathrm{u}}$ & $\varepsilon_{\mathrm{f}}$ & - \\
\hline & {$[\mathrm{kNm}]$} & {$[\mathrm{kNm}]$} & {$[\mathrm{kNm}]$} & {$[\mathrm{kNm}]$} & {$[\mathrm{mm}]$} & {$[\% 0]$} & {$[-]$} \\
\hline $\mathrm{BC}$ & 55 & 266 & - & 272 & 66.2 & - & Steel yielding \\
\hline B0 & 70 & 318 & 332 & 332 & 56.5 & 5.9 & Debonding \\
\hline B0A & 72 & 321 & 332 & 361 & 98.6 & 7.8 & Debonding, slipping out from anchorages \\
\hline B30 & 111 & 371 & 393 & 424 & 147.6 & 15.8 & $\begin{array}{l}\text { Debonding, slipping out from anchorages } \\
\text { and strips rupture }\end{array}$ \\
\hline B40 & 120 & 394 & 400 & 415 & 97.5 & 16.4 & $\begin{array}{l}\text { Debonding, slipping out from anchorages } \\
\text { and strips rupture }\end{array}$ \\
\hline B50 & 136 & 419 & 428 & 428 & 57.6 & 16.7 & $\begin{array}{l}\text { Simultaneous debonding and slipping out } \\
\text { from anchorages }\end{array}$ \\
\hline
\end{tabular}

beams (B0-B50), the ultimate moment is defined as the failure load of the CFRP strengthening system (regardless of failure mode). The failure modes of all strengthened beams are shown in Fig. 14 and described below as follows.

The failure mode and the respective ultimate moment of the control beam (BC) were considered resulting from an excessive strain of the steel reinforcement due to plastic deformation. After reaching the load of $272 \mathrm{kNm}$, the beam's deflection started increasing without further load increase. The crack width in the middle of the beam span reached $2 \mathrm{~mm}$. Therefore, this load value was considered to be an ultimate load-bearing capacity; the test was ceased, and the beam was unloaded.

The failure of the passively strengthened $\mathrm{B} 0$ beam resulted from the intermediate crack debonding, initiated in the area of high bending moment and shear force (loading point section) and progressing towards strip ends. At the time of failure (under the load of $332 \mathrm{kNm}$ ), one strip debonded completely from the concrete surface, while the other remained attached in the end section of about $20 \mathrm{~cm}$ (Fig. 14a). After debonding, the strips were not fully destroyed, only minor surface damages occurred. The passively strengthened B0A beam with anchorages failed when the previously debonded strips slipped out of the steel anchorages. A few phases of failure could be recognised in this case. First, the CFRP strips debonded from the concrete surface (as with the B0 beam), and the strips started working as a tie (Fig. 14b). Then, as a result of the continuous load increase, the first and subsequently the second strip slipped out from the anchorage, so that the whole strengthening was damaged under the load of $361 \mathrm{kNm}$. The subsequent load drops visible in Fig. 13 represent the subsequent phases of failure of the beam strengthening. Besides the strips slipping out of the anchors, there were no major strip damages and both strips were still attached to the beam in the one anchorage (Fig. 14b).

The failure of the actively strengthened B30 beam, as in the case of previous beams, was initiated by debonding the strip near the loading point section. In the next phase, both CFRP strips were damaged successively, which is visible as the load drops in the load-deflection plot (Fig. 13). In this case, the strips were destroyed after slipping out from the anchorages. They suddenly broke into lots of small pieces under the load of $424 \mathrm{kNm}$. The total strips destruction, however, was not related to exceeding CFRP tensile strength. The CFRP strains at the moment of failure were far from their ultimate value. This failure mode was an after-effect of the release of a huge amount of energy due to slipping out of the tensioned strips from the anchorages. In addition, the CFRP strengthening failure was accompanied by the concrete crushing of the top beam's surface near the loading point (Fig. 14c). The failure mode of the next actively strengthened B40 beam was very similar to the B30 beam's failure. However, in this case, only one strip was destroyed after slipping out from the anchorages under the load of $415 \mathrm{kNm}$ (Fig. 14d). Finally, the failure mode of the actively strengthened B50 beam was sudden and violent. The strips slipping out from the anchorages were not preceded by strips debonding (Fig. 14e). These two failure phenomena occurred simultaneously and the strips slipped out successively, which can be seen in Fig. 13. In this case, after strengthening failure (debonding and slipping out) under the load of $428 \mathrm{kNm}$, the strips were not destroyed as in previous beams. 


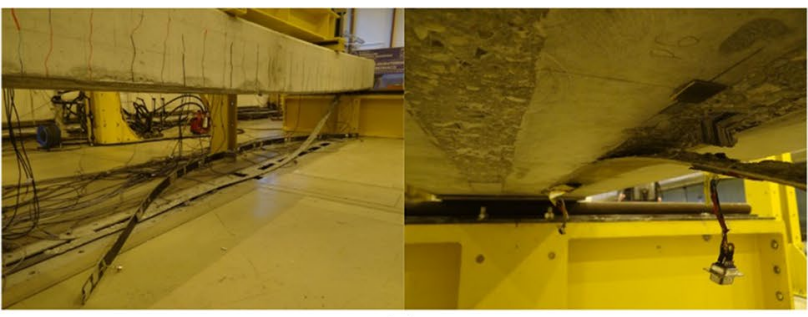

(a)

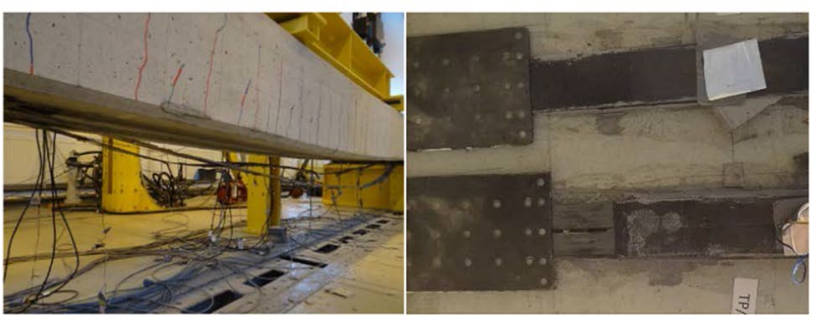

(b)

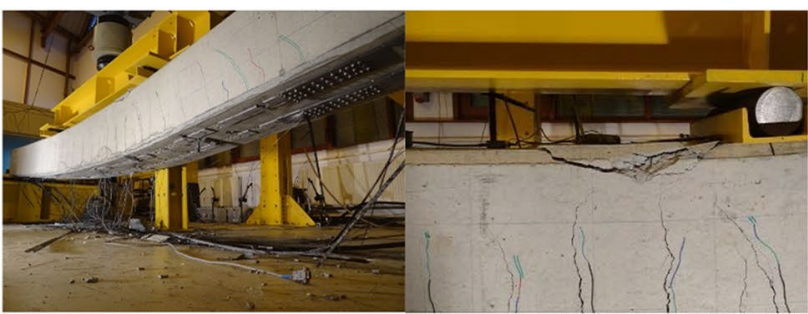

(c)

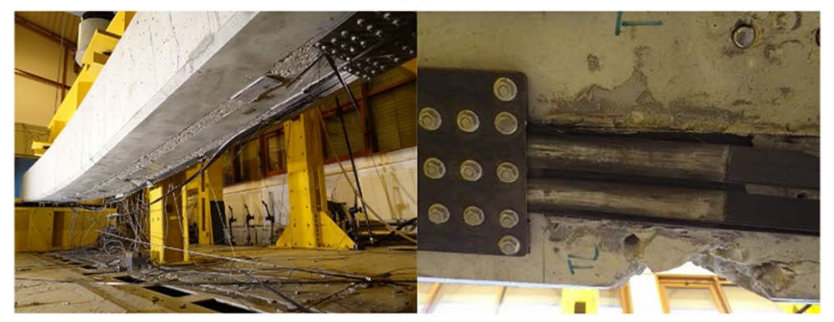

(d)

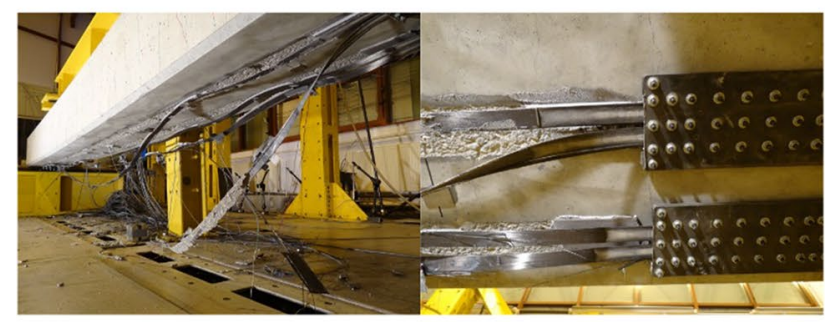

(e)

Fig. 14 Failure modes of the strengthened beams: a B0, b B0A, c B30, d B40, e B50

\section{Discussion of results}

\subsection{Indicators of strengthening efficiency}

The strengthening efficiency in the particular work phases is an individual feature of a strengthened beam, mainly dependent on its geometrical dimensions, CFRP strengthening composition (number and cross-section of the strips), as well as the method of strengthening (passive or active) and, in the latter case, the strip prestressing level. Analysis of the results and detailed assessment of the behaviour of CFRP strengthened beams under static load were based on several indicators of strengthening efficiency. These indicators were used to assess the effect of strips anchoring in passively strengthened beams, the effect of strips tensioning in active strengthening as well as the effect of the prestressing level in actively strengthened beams, on the structural behaviour of CFRP strengthened beams. To determine the values of particular indicators, the data from Table 7 were taken into account. The following indicators of strengthening efficiency were considered in this study (Table 8):

- the strengthening efficiency of the uncracked phase: $\eta_{c r}=\left(M_{c r i}-M_{c r 1}\right) / M_{c r 1}$ (the ratio of difference of cracking moment in the strengthened beam and the control one to the cracking moment in the control beam);

- the strengthening efficiency of the post-cracked phase: $\eta_{e}=\left(M_{y i}-M_{y 1}\right) / M_{y 1}$ (the ratio of difference of steel yield moment in the strengthened beam and the control one to steel yield moment in the control beam);

- the strengthening efficiency of the post-yielded phase: $\eta=\left(M_{u i}-M_{u 1}\right) / M_{u 1}$ (the ratio of difference of ultimate load-carrying capacity of the strengthened beam and the control one to the ultimate load-bearing capacity of the control beam);

- the level of a CFRP strip utilisation: $\eta_{\sigma}=\sigma_{\text {max }} / f_{f u}$ (the ratio of maximum strip stress to the tensile strength of CFRP composite),

- the ratio of ultimate load-bearing capacity to debonding moment: $\mu_{M}=M_{u} / M_{d}$;

- the ratio of plastic displacement after strip debonding: $\mu_{\Delta}=\Delta_{u} / \Delta_{d}$ (ratio of the beam deflection during failure to the beam deflection during debonding).
Table 8 Indicators used to assess the beam strengthening efficiency

\begin{tabular}{lllllll}
\hline Beam & $\eta_{c r}$ & $\eta_{e}$ & $\eta$ & $\eta_{\sigma}$ & $\mu_{M}$ & $\mu_{\Delta}$ \\
\hline B0 & $27 \%$ & $20 \%$ & $22 \%$ & $30 \%$ & 1.00 & 1.00 \\
B0A & $31 \%$ & $21 \%$ & $33 \%$ & $39 \%$ & 1.09 & 2.19 \\
B30 & $102 \%$ & $39 \%$ & $56 \%$ & $79 \%$ & 1.08 & 2.48 \\
B40 & $118 \%$ & $48 \%$ & $53 \%$ & $82 \%$ & 1.01 & 1.73 \\
B50 & $147 \%$ & $58 \%$ & $57 \%$ & $84 \%$ & 1.00 & 1.00 \\
\hline
\end{tabular}


Besides the efficiency concerning ultimate load-bearing capacity, the type of used strengthening system does not have a major effect on these parameters. However, the level of CFRP strip utilisation strongly depends on the parameters of the incorporated strengthening system. It is also an individual feature of such a system, dependent on the efficiency of its constituent elements (mainly anchorages). The last two parameters $\left(\mu_{M}, \mu_{\Delta}\right)$ are particularly important to assess the strengthening efficiency of the novel system because they characterise the global safety of the strengthened structure (in this case: the RC beam). The ratio of ultimate load-bearing capacity to debonding moment of CFRP strip characterises a safety margin resulting from anchorages and post-failure behaviour of the beam after debonding. The ratio of plastic displacement after strip debonding characterises the elastic behaviour of the beam in the post-failure phase, which results in the rate of strengthening failure. The lower the value of this ratio is, the more violent the failure is.

The following subsections contain the analysis of the determined indicators listed in Table 8 and other parameters characterising the behaviour of the strengthened RC beams under static load, such as stiffness, cracking pattern, deflection and failure modes.

\subsection{Effect of strips anchoring}

The use of the strip anchorages in passive strengthening did not significantly affect the static behaviour of the beams until strip debonding. The stiffness of B0 and B0A beams in this phase, characterised by the load-deflection relationship (Fig. 13) as well as the number and widths of cracks (Table 2), was almost the same. The strengthening efficiency of the uncracked phase $\left(\eta_{c r}\right)$ and post-cracked phase $\left(\eta_{e}\right)$ of the B0 and B0A beams have similar values-the difference was $4 \%$ and $1 \%$, respectively (Table 7 ). The more significant differences occurred in the strengthening efficiency of the post-yielded phase $(\eta)$ related to the ultimate load-bearing capacity of the strengthened beams, which is associated with their failure modes. In the case of the B0 beam, strengthened passively without anchorages, the strengthening was destroyed due to the intermediate crack debonding (see description in Sect. 4.4). The use of the anchorages in the B0A beam (as well as in subsequent prestressed beams) affected the appearance of an additional post-debonding phase, i.e. after debonding up to failure. In this phase, the anchored CFRP strips worked as ties, continuing to carry the load. The tie force was transferred to the beams only at the points of strips anchoring. In both passively strengthened beams, the strip debonding occurred at the load of $332 \mathrm{kNm}$. For the $\mathrm{B} 0$ beam, it was the value of ultimate load-bearing capacity. However, due to strip anchoring, the ultimate loadbearing capacity of the B0A beam increased to $361 \mathrm{kNm}$ (up to slipping out the strips from the anchorages), and the strengthening efficiency of the post-yielded phase $(\eta)$ raised by $9 \%$ as compared to the $\mathrm{B} 0$ beam.

In the case of the B0 beam, the ratio of ultimate loadbearing capacity to debonding moment $\left(\mu_{M}\right)$ was 1.00 because the failure took place just after the strip debonding, without a clear warning signal. In the case of the B0A beam, after the strip debonding, the anchorages allowed for further load increase until the debonding took place $\left(\mu_{M}=1.09\right)$. The anchorages also allowed for increasing ductility of the beams due to ductile (plastic) behaviour of the beams after debonding (Fig. 13). When using the anchorages in the B0A beam, the ratio of the beam deflection during failure to the beam deflection during debonding $\left(\mu_{\Delta}\right)$ was 2.19 , whereas in the case of the B0 beam it was only 1.00 due to sudden failure just after debonding. Using the S-type anchorages, which are more efficient [27], resulted in increasing the post-debonding ductility of the B30 beam as compared to the B0A beam with the $\mathrm{N}$-type anchorages. In this case the ratio $\mu_{\Delta}$ increased to 2.48 .

In the B0 beam (without anchorages), the maximum CFRP strain at failure was $5.9 \%$, while higher strains of $7.8 \%$ were recorded in the beam strengthened with the anchored strips (B0A). Thus the level of CFRP strip utilisation increased as a result of using the anchorages in passive strengthening. For the B0 beam, the level of a CFRP strip utilisation $\left(\eta_{\sigma}\right)$ was about $30 \%$ which seems to be typical for passive strengthening without anchorages [41]. After using the $\mathrm{N}$-type anchorages in the B0A beam, this level increased up to $39 \%$. However, it was not a satisfying result. The efficiency of the novel anchorages (i.e. the ratio of failure load of anchorages to CFRP tensile strength) determined in tensile tests conducted on fullscale models of $\mathrm{N}$-type anchorages was $67 \%$, on average [27]. Therefore, the significant loss of the $\mathrm{N}$-type anchorage efficiency obtained in the B0A beam test was, most probably, caused by imperfections arising during the manufacturing of anchorages. Furthermore, the inaccuracies resulted from the fact that the anchorages were installed on the beam in a non-axial way, caused the reduction of the carrying capacity of the strengthening system. For this type of anchorages, the ideal linearity of the entire system is required to install and operate correctly [27]. The level of CFRP utilisation in the B0A beam as well as its ultimate load-bearing capacity could probably be increased using S-type anchorages, in the case of which similar problems were not observed. This type of anchorage behaved well in the cases of the B30-B50 beams, in which level of CFRP utilisation $\left(\eta_{\sigma}\right)$ was around $80 \%$. Moreover, the efficiency of S-type anchorages attached to the RC beams was higher as compared to the efficiency of these anchorages obtained during the model tensile test (approx. 70\% [27]). This 
increase in CFRP utilisation was due to the presence of epoxy adhesive layer between CFRP strip and concrete surface and smaller values of the CFRP strains near the anchorages as compared to values near the middle of the span (Fig. 10).

\subsection{Effect of strips tensioning}

Owing to strengthening the RC beam with tensioned CFRP strips, both the cracking moment and the steel yielding moment were increased. The CFRP prestressed beams also showed significantly higher ultimate load-bearing capacity. Therefore, the increase in the strengthening efficiency was observed in each phase of RC beam behaviour due to strips tensioning. The increase in the cracking moment in passively strengthened beams (B0, B0A) was relatively small and amounted to approximately $30 \%$ in comparison with the control beam (BC). However, in all prestressed beams, the strengthening efficiency of the uncracked phase $\left(\eta_{c r}\right)$ was over $100 \%$ (Table 8), which means that the cracking moment was more than doubled. Thus, the strip tensioning results in a significant increase in the cracking moment and the extension of the uncracked phase of RC beam behaviour, both in relation to the control beam and the beams strengthened passively. The increase in the cracking moment in the prestressed beams in relation to the beams with passive strengthening was dependent on the strip prestressing level and ranged from $60 \%$ for the B30 beam to $95 \%$ for the B50 beam. The extension of the uncracked phase of beam behaviour is an unquestionable advantage of the strips tensioning. The tests revealed that the prestressing of the RC beams also caused a significant extension of their post-cracked phase of behaviour under static load. The strengthening efficiency of this phase $\left(\eta_{e}\right)$ in passively strengthened beams was about $20 \%$, and due to strip tensioning its value increased to $39 \%$ for the B30 beam and 58\% for the B50 beam. The observed increase in the steel yielding moment caused by strip tensioning in comparison to passive strengthening amounted from 17 to $32 \%$, depending on the level of prestressing.

The method of strengthening also has a significant impact on strengthening efficiency concerning ultimate load-bearing capacity. In the case of prestressed beams, the strengthening efficiency of post-yielded phase $(\eta)$ of the B0 and B0A beams was $22 \%$ and $33 \%$, respectively, while for the prestressed beams it was in the range of 53-57\% (Table 8). Thus, the ultimate load-bearing capacity in prestressed beams was increased by around $25-30 \%$ in comparison with the B0 beam and around $15-20 \%$ when it comes to the B0A beam.

The CFRP strengthening increased the stiffness of RC beams, relatively low in the case of passive strengthening and much more significant in the case of active strengthening. The increase in the stiffness after strengthening can be seen in Figs. 12 and 13 showing a comparison of deflections for all tested beams. The increase in the stiffness results in decreasing the deflection. For example, at the load of 250 $\mathrm{kNm}$, the deflection of passively strengthened beams was about $15 \%$ less than the deflection of the control beam. In the case of prestressed beams, the difference was much greater, ranging from $20 \%$ for the B 30 beam to $47 \%$ for the B50 beam (Fig. 12). The substantial increase in the stiffness due to CFRP tensioning is also visible in a limited cracking of the strengthened beams. The crack patterns of subsequent beams at the load of $250 \mathrm{kNm}$ indicate a significant reduction in the total crack width in the case of prestressed beams (Fig. 7). Regarding the passively strengthened beams, the number of cracks was larger than in the control beam, while the width of particular cracks was smaller. Such a change in the crack distribution results from the bonding between a strip and concrete, which reduces the spacing of cracks. In the prestressed beams, the number of cracks and crack width was significantly reduced in comparison to the passively strengthened beams. In all strengthened beams, a reduction of the total crack width was also noted (Table 2). At the load of $250 \mathrm{kNm}$ the total crack width was reduced by around $30 \%$ in the case of passively strengthened beams and around 43\% for the prestressed beams (Table 2). In addition, the specified load level in the control beam caused cracks with a width of $0.40 \mathrm{~mm}$, while cracks in strengthened beams did not exceed $0.20 \mathrm{~mm}(0.25 \mathrm{~mm}$ in the case of B30 beam). Furthermore, in the prestressed beams, there was a smaller number of wider cracks. CFRP tensioning significantly reduces the cracking of RC beams, which is indicated by both the number of cracks along the beam and the crack width being reduced. As a result, it improves the operational parameters and increases the durability of strengthened RC structures.

As a result of CFRP strengthening of the $\mathrm{RC}$ beams, the strains of concrete and reinforcing steel under successive load levels were significantly reduced (Figs. 8, 9). Regarding the passively strengthened beams, there was a $21 \%$ and $9 \%$ reduction of concrete strains at the load of $250 \mathrm{kNm}$, for the $\mathrm{B} 0$ and $\mathrm{B} 0 \mathrm{~A}$ beams, respectively, and a $28 \%$ reduction of reinforcing steel strains in both beams. In the case of prestressed beams (B30-B50), the strains of both materials were reduced to a greater extent, ranging from 24 to $36 \%$ in the case of concrete and from 45 to $55 \%$ in the case of reinforcing steel (Tables 3 and 5).

The reduction of beam utilisation due to prestressing resulted in limiting the strains of CFRP strips. At the load of $250 \mathrm{kNm}$, the strains of the CFRP strips in the prestressed beams were over $20 \%$ lower (on average) as compared to the passively strengthened beams (Fig. 11). It can be also observed in Figs. 8, 9 and 11 that the residual (permanent) strains of concrete, steel and CFRP strips, which remained after previous loading stages, were lower in the prestressed beams in comparison with the passively strengthened ones. 
Tensioning of the strips affected the level of a CFRP strip utilisation $\left(\eta_{\sigma}\right)$. For the B0A beam this level was 39\%, while for the B30 beam it was $79 \%$. A double increase in this indicator was caused by introducing initial CFRP strains during tensioning as well as using more effective S-type anchorages in prestressed beams (B30-B50). Change of the strengthening method, from passive to active, have not significantly affected the ratio of ultimate load-bearing capacity to debonding moment $\left(\mu_{M}\right)$ and the ratio of plastic displacement after strip debonding $\left(\mu_{\Delta}\right)$. Values of these indicators for beams B0A and B30 are similar.

\subsection{Effect of strips prestressing level}

The prestressing level had a significant influence on the behaviour of actively strengthened beams (B30-B50). The strengthening efficiency of the uncracked phase $\left(\eta_{c r}\right)$ increased following the increase in the prestressing level (Table 8). The increase in the cracking moment of the B40 and B50 beams in comparison with the B30 beam was about $8 \%$ and $23 \%$, respectively. The strengthening efficiency in the post-cracked phase $\left(\eta_{e}\right)$ also increased when prestressing level increased (Table 8). However, the increase in the yielding moment of the B40 and B50 beams in comparison with the B30 beam was lower-6\% and 13\%, respectively. A similar relationship was noted in the case of debonding moment. In the B40 and B50 beams, it was 2\% and 9\% larger in comparison with the B30 beam, respectively. The prestressing level had a minor effect on the ultimate moment. All actively strengthened beams failed at a similar value of testing load in the range of $415-428 \mathrm{kNm}$. The differences between the ultimate moments of the prestressed beams did not exceed 2\%. Moreover, the ultimate moment of the beam B30 (with the lowest prestressing level) was higher than in the case of beam B40. Due to that, the strengthening efficiency in the post-yielded phase $(\eta)$ of all prestressed beams was similar and amounted to around 55\%. The relationships between cracking, yielding, debonding as well as ultimate moments depending on the prestressing level are presented in Fig. 15.

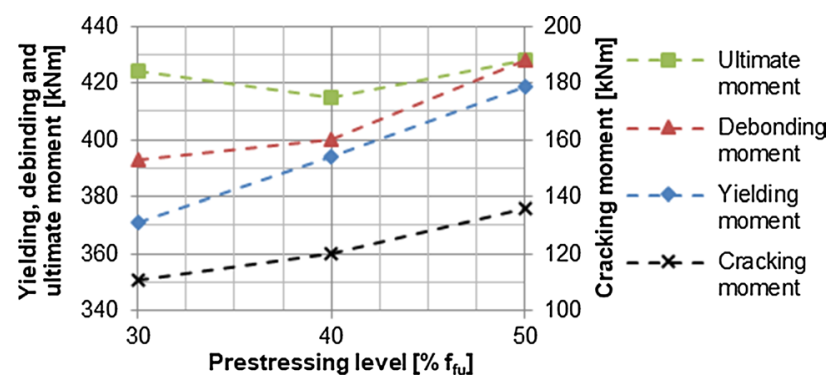

Fig. 15 Influence of prestressing level on cracking, yielding, debonding and ultimate moments of the prestressed beams
The influence of prestressing level on changes in the stiffness of prestressed beams can be observed in Fig. 13, showing the load-displacement $(\mathrm{M}-\Delta)$ relationships. In the uncracked phase, this influence is negligible. However, in the post-cracked phase, the slope of M- $\Delta$ curves for each prestressed beam is different, which results in a reduction of deflections in subsequent prestressed beams at similar load. For example, in the case of the testing load of $250 \mathrm{kNm}$, the reduction of deflection of the $\mathrm{B} 40$ and $\mathrm{B} 50$ beams against the B30 beam was $18 \%$ and $25 \%$, respectively. The prestressing level affects also the cracking mode. The maximum crack width at the load of $250 \mathrm{kNm}$ in the case of the B30 was $0.25 \mathrm{~mm}$, while for B40 and B50 beams it was $0.20 \mathrm{~mm}$ (Fig. 7). The total crack width slightly decreased (from 3.5 to $3.4 \mathrm{~mm}$ ) with increasing the prestressing level (Table 2). The largest number of cracks (32) among prestressed beams was noted in the B40 beam. Therefore, it can be concluded that the increase in the strip prestressing level results in limiting the number and the total width of the cracks, but in this study, this impact is small and hardly visible.

In the prestressed beams, the total strains of the CFRP strip $\varepsilon_{\mathrm{p}}+\varepsilon_{1}$ (i.e. initial strains caused by tensioning plus strains from external load) increased with increasing the prestressing level and just before failure they were equal to $15.8 \%$, $16.4 \%$ and $16.7 \%$ o for B30, B40 and B50 beams, respectively. Taking into account the obtained CFRP ultimate strains it was revealed, that the CFRP material was utilised in 79\%, 82\% and 84\% for B30, B40 and B50 beams, respectively. Thus, a slight increase in the CFRP strip utilisation $\left(\eta_{\sigma}\right)$ was observed along with the increase in the prestressing level. However, CFRP strains under testing load $\varepsilon_{1}$ (excluding the initial strains) decreased with increasing the prestressing level. This is related to the higher stiffness of the beams with higher prestressing level. Strains distributions along the CFRP strips under the load of $400 \mathrm{kNm}$ (close to failure) are presented in Fig. 16.

The prestressing level of the CFRP strips had a significant influence on the failure mode of the beams. In the case of B30 and B40 beams, the failure modes had long-lasting, gradual character. After strips debonding, an additional

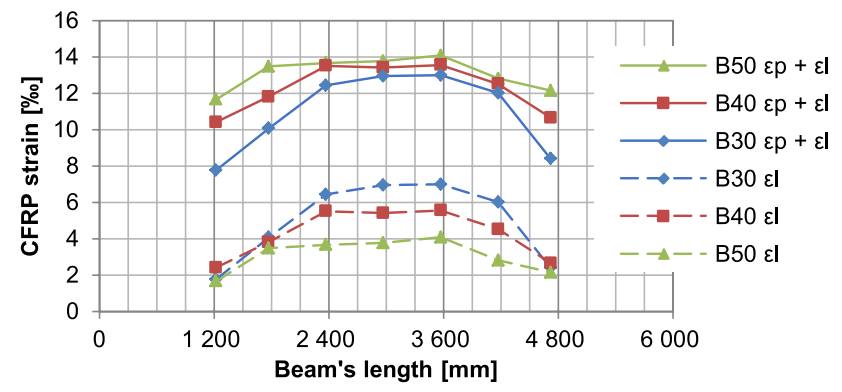

Fig. 16 Strains distributions along the CFRP strips under the load of $400 \mathrm{kNm}$ 
phase of the beam's behaviour occurred and then failure was due to slipping out the strips from the anchorages. In the post-debonding phase, CFRP strains were approximately equal along the strip and the strips worked like ties (Fig. 10). The failure mode of the B50 beam with the highest prestressing level was different. The B50 beam was suddenly damaged due to slipping out of the strips from anchorages, without any previous debonding signs. These two phenomena, debonding and slipping out from the anchorages of both strips, occurred at the same moment. This was due to the higher initial CFRP strains induced by tension.

The ratio of the ultimate moment to the debonding moment $\left(\mu_{M}\right)$ in the $\mathrm{B} 30$ beam with the lowest prestressing level was 1.08. In beams with higher prestressing level, this ratio decreased to 1.01 for the B40 beam and 1.00 for the B50 beam. In the latter case, the strip debonding occurred at the same time as the failure of strengthening (slipping out from the anchorages). Increasing the strip prestressing level up to $50 \% \mathrm{f}_{\mathrm{fu}}$ resulted in the loss of an additional safety margin related to the post-debonding phase of the beam's behaviour. A similar dependence occurred in the case of the ratio of beam deflections after strip debonding $\left(\mu_{\Delta}\right)$. The higher the value of this ratio, the behaviour of the beam after debonding is more ductile and the failure signs are more visible. In the case of the $\mathrm{B} 30$ and $\mathrm{B} 40$ beams, the ratio $\mu_{\Delta}$ was 2.48 and 1.73, respectively. However, in the case of the B50 beam, in which the sudden failure occurred, the ratio $\mu_{\Delta}$ was 1.00. Therefore, the ductility of the prestressed beams was decreased as the strip prestressing level was increased.

Due to a significant change in the failure mode of the B50 beam (with strips tensioned up to $50 \% \mathrm{f}_{\mathrm{fu}}$ ), which was abrupt and did not show any prior signs, it seems to be justified to apply the strips maximally tensioned up to $40 \%$ $\mathrm{f}_{\mathrm{fu}}$ to strengthen the RC beams using the novel prestressing system. This value corresponds to the initial CFRP strains of $8 \% o$ and the prestressing force of $108 \mathrm{kN}$ for one strip. However, a higher prestressing level could be applied, but then sudden failure mode can occur and this fact should be taken into account at the design stage. These conclusions concern only the particular system which was used to strengthen the tested beams. In the case of this system, the optimal prestressing level is closely related to the limited efficiency of steel anchorages [27].

\section{Conclusions}

The experimental study on the RC beams strengthened passively and actively with the novel CFRP prestressing system was presented in the paper. The five full-scale RC beams were strengthened with passive strips, without and with mechanical anchorages at their ends, as well as with strips tensioned by the novel CFRP prestressing system with three various prestressing levels ranging from 30 to $50 \%$ of the CFRP tensile strength. All beams were tested under static flexural load up to failure and they were investigated in a full range of flexural behaviour, including the post-debonding phase. Based on the results of the tests and analysis of results, the following conclusions can be drawn.

- The most important result of CFRP passive strengthening of RC beams was the increase in their ultimate loadbearing capacity in the range of $22-33 \%$ for the beams B0 and B0A, respectively. However, strengthening with passively bonded CFRP strips resulted only in a slight increase in the RC beams' stiffness, which could be observed in slightly limited deflection and cracking, and allowed to increase the steel yielding moment by $20 \%$ as compared to the control beam (BC).

- The use of the anchorages at the passive strip ends affected the appearance of the additional post-debonding phase of the beam's behaviour (up to failure after debonding), contributed to the increase in ultimate loadbearing capacity by $9 \%$ as compared to the beam passively strengthened without anchorages, to the increase in the strip utilisation level (about 9 percentage points) and to change of the failure mode.

- Strengthening the RC beams with the tensioned CFRP strips caused a considerable increase in the ultimate loadbearing capacity (by more than 50\%). The RC beams' prestressing by CFRP strips caused also the increase in the cracking moment in the range of $102-147 \%$, the yielding moment in the range of $39-58 \%$ as well as the stiffness of the beams in the range of $20-47 \%$, as compared to the control beam.

- Increasing the strip prestressing level did not affect the ultimate load-bearing capacity of the RC beams, but it had a significant influence on other parameters describing beams' behaviour. Once the strip prestressing level increased from 30 to $50 \%$ of $f_{\mathrm{u}}$, there was an increase in the cracking moment (23\%) and the yielding moment (13\%), as well as a reduction of deflection (25\%) and cracking (3\%) of the beams. A slight increase in the level of CFRP utilisation has also been observed (5 percentage points).

- Evaluating the failure mode of the tested beams, the optimal prestressing level of the CFRP strip in the novel strengthening system has been determined, equalling $40 \% f_{\text {fu }}$. Up to this level, a ductile failure mode of strengthening occurs, which allows to early identify the possible damage caused by overloading the strengthened structure. Owing to the efficiency of the anchorages, the strengthening system enables to use of a higher prestressing level of $50 \%$ or even $60 \% f_{\text {fu }}$. However, the sudden failure mode of CFRP strengthening should be taken into account in strengthening design. 
In general, the conclusions of this study in terms of the behaviour of RC beams strengthened with CFRP strips (passive or active) under static load are similar to other research results described in the literature, which reveal that the novel system works properly. Moreover, several particular parameters and indicators have been determined to be used in further development of the system itself as well as in the design of the CFRP strengthening of RC structures using the system. The system has been already implemented on-site to strengthen several RC and steel bridges in Poland [31].

Acknowledgements This work was supported by the Polish National Centre of Research \& Development within the framework of the research project entitled: Innovative System for Strengthening of Structures with Prestressed Strips of Carbon Fibre Reinforced Composites [Grant Number POIG.01.03.01-18-010/12].

Author contributions BP: data curation, methodology, visualization, investigation, writing - original draft preparation. TS: conceptualization, methodology, supervision, writing_reviewing and editing.

Availability of data and material All data are available from the corresponding author on request.

Code availability Not applicable.

\section{Declarations}

Conflict of interest The authors declare that they have no known competing financial interests or personal relationships that could have appeared to influence the work reported in this paper.

Ethics approval All ethical requirements of the journal are met. This article does not contain any studies with human participants or animals performed by any of the authors.

Consent to participate All authors agree to be the author of the publication.

Consent for publication All authors agree to submit their publications to this journal.

Open Access This article is licensed under a Creative Commons Attribution 4.0 International License, which permits use, sharing, adaptation, distribution and reproduction in any medium or format, as long as you give appropriate credit to the original author(s) and the source, provide a link to the Creative Commons licence, and indicate if changes were made. The images or other third party material in this article are included in the article's Creative Commons licence, unless indicated otherwise in a credit line to the material. If material is not included in the article's Creative Commons licence and your intended use is not permitted by statutory regulation or exceeds the permitted use, you will need to obtain permission directly from the copyright holder. To view a copy of this licence, visit http://creativecommons.org/licenses/by/4.0/.

\section{References}

1. Saadatmanesh H, Ehsani MR. RC beams strengthened with GFRP plates. I: experimental study. J Struct Eng. 1991;117(11):3417-33. https://doi.org/10.1061/(ASCE)0733-9445(1991)117:11(3417).

2. Triantafillou TC, Deskovic N, Deuring M. Strengthening of concrete structures with prestressed fiber reinforced plastic sheets. ACI Struct J. 1992;89(3):235-44.

3. Hollaway LC, Teng JG. Strengthening and rehabilitation of civil infrastructures using fibre-reinforced polymer (FRP) composites. Cambridge: Woodhead Publishing; 2008.

4. Wu HC, Eamon CD. Strengthening of concrete structures using fiber reinforced polymers (FRP): design, construction and practical applications. Cambridge: Woodhead Publishing; 2017.

5. Meier U. Strengthening of structures using carbon fibre/epoxy composites. Constr Build Mater. 1995;9(6):341-51. https://doi. org/10.1016/0950-0618(95)00071-2.

6. Hollaway LC. A review of the present and future utilisation of FRP composites in the civil infrastructure with reference to their important in-service properties. Constr Build Mater. 2010;24(12):2419-45. https://doi.org/10.1016/j.conbuildmat. 2010.04.062.

7. Garden HN, Hollaway LC. An experimental study of the influence of plate end anchorage of carbon fibre composite plates used to strengthen reinforced concrete beams. Compos Struct. 1998;42(2):175-88. https://doi.org/10.1016/S0263-8223(98) 00070-1.

8. Qeshta IM, Shafigh P, Jumaat MZ. Research progress on the flexural behaviour of externally bonded RC beams. Arch Civ Mech Eng. 2016;16(4):982-1003. https://doi.org/10.1016/j. acme.2016.07.002.

9. Jankowiak I. Analysis of RC beams strengthened by CFRP strips-experimental and FEA study. Arch Civ Mech Eng. 2012;12(3):376-88. https://doi.org/10.1016/j.acme.2012.06. 010 .

10. Derkowski W. Fatigue life of reinforced concrete beams under bending strengthened with composite materials. Arch Civ Mech Eng. 2006;6(4):33-47. https://doi.org/10.1016/S1644-9665(12) 60274-X.

11. Deng J, Rashid K, Li X, Xie Y, Chen S. Comparative study on prestress loss and flexural performance of rectangular and $\mathrm{T}$ beam strengthened by prestressing CFRP plate. Compos Struct. 2021;262: 113340. https://doi.org/10.1016/j.compstruct.2020. 113340.

12. Jumaat MZ, Rahman MM, Rahman MA. Review on bonding techniques of CFRP in strengthening concrete structures. Int J Phys Sci. 2011;6(15):3567-75. https://doi.org/10.5897/IJPS10.376.

13. Aslam M, Shafigh P, Jumaat MZ, Shah SNR. Strengthening of $\mathrm{RC}$ beams using prestressed fiber-reinforced polymers-a review. Constr Build Mater. 2015;82:235-56. https://doi.org/10.1016/j. conbuildmat.2015.02.051.

14. Mohee FM, Al-Mayah A, Plumtree A. Anchors for CFRP plates: state-of-the-art review and future potential. Compos B Eng. 2016;90:432-42. https://doi.org/10.1016/j.compositesb.2016.01. 011.

15. Kalfat R, Al-Mahaidi R, Smith S. Anchorage devices used to improve the performance of reinforced concrete beams retrofitted with FRP composites: a-state-of-the-art-review. J Compos Constr. 2013;17(1):14-33. https://doi.org/10.1061/(ASCE)CC. 1943-5614.0000276.

16. Andrä H-P, Maier M. Post-strengthening with externally bonded prestressed CFRP strips. In IABSE Congress Report. International 
Association for Bridge and Structural Engineering, 2000 (p 1507-1514).

17. Berset T, Schwegler G, Trausch L. Verstärkung einer autobahnbrücke mit vorgespannten CFK-lamellen [strengthening of a motorway bridge with prestressed CFRP strips]. Tec21. 2002;128(22):22-9. https://doi.org/10.5169/seals-80433 (in German).

18. Suter R, Jungo D. Vorgespannte CFK-Lamellen zur Verstärkung von Bauwerken [Prestressed CFRP strips for strengthening structures]. Beton-und Stahlbetonbau. 2001;96(5):350-8. https://doi. org/10.1002/best.200100370 (in German).

19. Correia L, Teixeira T, Michels J, Almeida JA, Sena-Cruz J. Flexural behaviour of RC slabs strengthened with prestressed CFRP strips using different anchorage systems. Compos B Eng. 2015;81:158-70. https://doi.org/10.1016/j.compositesb.2015.07. 011 .

20. Yang J, Haghani R, Al-Emrani M. Innovative prestressing method for externally bonded CFRP laminates without mechanical anchorage. Eng Struct. 2019;197: 109416. https://doi.org/10. 1016/j.engstruct.2019.109416.

21. Woo SK, Nam JW, Kim JHJ, Han SH, Byun KJ. Suggestion of flexural capacity evaluation and prediction of prestressed CFRP strengthened design. Eng Struct. 2008;30(12):3751-63. https:// doi.org/10.1016/j.engstruct.2008.06.013.

22. Yang DS, Park SK, Neale KW. Flexural behaviour of reinforced concrete beams strengthened with prestressed carbon composites. Compos Struct. 2009;88(497):508. https://doi.org/10.1016/j. compstruct.2008.05.016.

23. Yu P, Silva PF, Nanni A. Flexural strength of reinforced concrete beams strengthened with prestresses carbon fiber-reinforced polymer sheets-part II. ACI Struct J. 2008;105(1):11-20.

24. You YC, Choi KS, Kim JH. An experimental investigation on flexural behaviour of RC beams strengthened with prestressed CFRP strips using a durable anchorage system. Compos B Eng. 2012;43(8):3026-36. https://doi.org/10.1016/j.compositesb.2012. 05.030 .

25. Kałuża M, Ajdukiewicz A. Comparison of behaviour of concrete beams with passive and active strengthening by means of CFRP strips. ACEE J Arch Civ Eng Env. 2008;1(2):51-64.

26. Kotynia R, Walendziak R, Stoecklin I, Meier U. RC slabs strengthened with prestressed and gradually anchored CFRP strips under monotonic and cyclic loading. J Compos Constr. 2010;15(2):16880. https://doi.org/10.1061/(ASCE)CC.1943-5614.0000081.

27. Piątek B, Siwowski T, Michałowski J, Błażewicz S. Flexural strengthening of RC beams with prestressed CFRP strips: development of novel anchor and tensioning system. J Compos Constr. 2020;24(3):04020015. https://doi.org/10.1061/(ASCE)CC.19435614.0001020

28. Siddika A, Al Mamun MA, Alyousef R, Amran YM. Strengthening of reinforced concrete beams by using fiber-reinforced polymer composites: a review. J Build Eng. 2019;25: 100798. https://doi.org/10.1016/j.jobe.2019.100798.

29. Kim YJ, Wight RG, Green MF. Flexural strengthening of RC beams with prestressed CFRP sheets: development of nonmetallic anchor systems. J Compos Constr. 2008;12(1):35-43. https:// doi.org/10.1061/(ASCE)1090-0268(2008)12:1(35).

30. Siwowski T, Michalowski J, Blazewicz S. Nowy system sprężania taśm kompozytowych CFRP do wzmacniania konstrukcji żelbetowych [the new CFRP prestressing system for strengthening concrete structures]. Inżynieria i Budownictwo. 2010;66:152-6 (in Polish).

31. Siwowski T, Piątek B, Siwowska P, Wiater A. Development and implementation of CFRP post-tensioning system for bridge strengthening. Eng Str. 2020;207: 110266. https://doi.org/10. 1016/j.engstruct.2020.110266.

32. CEN (European Committee for Standardization). EN 206. Concrete-specification, performance, production and conformity. Brussels: CEN; 2013

33. CEN (European Committee for Standardization). EN 1992-1-1. Eurocode 2: design of concrete structures-part 1-1: General rules and rules for buildings. Brussels: CEN; 2008.

34. CEN (European Committee for Standardization). EN 10002-1. Metallic materials-tensile testing-part 1: method of test at ambient temperature. Brussels: CEN; 2008.

35. ISO (International Organization for Standardization). ISO 527. Plastics-determination of tensile properties. Geneva: ISO; 2012.

36. CEN (European Committee for Standardization). EN 1465. Adhesives. Determination of tensile lap-shear strength of bonded assemblies. Brussels: CEN; 2009.

37. Piątek B, Siwowski T, Michałowski J, Błażewicz S. Development of bonded/riveted steel anchorages of prestressed CFRP strips for concrete strengthening. Materials. 2020;13(10):2217. https://doi. org/10.3390/ma13102217.

38. Piątek B, Siwowski T, Michałowski J, Błażewicz S. Experimental research on hybrid anchorages of prestressed composite strips for structural strengthening. J Compos Mater. 2021;55(24):3539-50. https://doi.org/10.1177/00219983211020349.

39. CEN (European Committee for Standardization). EN 1990. Eurocode: basis of structural design. Brussels: CEN; 2004.

40. CEN (European Committee for Standardization). EN 1991. Eurocode: actions on structures. Brussels: CEN; 2004.

41. Kotynia R. FRP composites for flexural strengthening of concrete structures: theory, testing, design. Lodz: Lodz University of Technology; 2019.

Publisher's Note Springer Nature remains neutral with regard to jurisdictional claims in published maps and institutional affiliations. 